\title{
HUBUNGAN JENIS ATAP DENGAN SUHU DAN KELEMBABAN KAMAR TIDUR DI DESA KARANGMANGU RW 01 KECAMATAN BATURRADEN KABUPATEN BENYUMAS TAHUN 2015
}

\author{
Prasetyo Udi Utomo ${ }^{1)}$, Tri Cahyono ${ }^{2)}$ \\ Jurusan Kesehatan Lingkungan, Politeknik Kesehatan Kemenkes Semarang, \\ Jl. Raya Baturaden KM 12 Purwokerto, Indonesia
}

\begin{abstract}
Abstrak
Kenyaman udara dalam ruangan ditentukan berdasarkan hubungan antara suhu udara, kelembaban udara dan gerakan angin. Survey awal yang dilakukan peneliti di Rw 1 dengan sampel 15 rumah ditemukan bahwa warga dalam 10 rumah mengeluhkan suhu udara yang panas. Jenis atap yang di gunakan dalam penelitian ini yaitu seng, asbes dan genteng. Tujuan penelitian ini ingin mengetahui ubungan jenis atap dengan suhu dan kelembaban kamar tidur di Desa Karangmangu Rw 01 Kecamatan Baturaden Kabupaten Banyumas tahun 2015. Jenis penelitian ini termasuk penelitian observasional, analisis menggunakan uji Chi square. Hasil penelitian terhadap 30 responden diketahui bahwa pengukuran suhu terdapat 18 rumah suhunya memenuhi syarat dan 12 rumah suhunya tidak memenuhi syarat sedangkan pengukuran kelembaban terdapat 15 rumah kelembabannya memenuhi syarat dan 15 rumah kelembabannya tidak memenuhi syarat. Hasil analisis menggunakan uji Chi square yaitu terdapat hubungan antara jenis atap dengan suhu dan kelembaban. Peneliti menyarankan untuk peneliti selanjutnya agar melakukan penelitian ini untuk waktu yang lebih lama.
\end{abstract}

Kata kunci : rumah sehat; suhu; kelembaban; jenis atap; kamar tidur; kesehatan lingkungan

\begin{abstract}
[Relationship Type of Roof with Temperature and Humidity of the Bedroom in the Village Karangmangu Rw 01 Districts Baturraden Banyumas Regency 2015]. Indoor air comfort is determined by the relationship between air temperature, air humidity and wind movement. Preliminary survey conducted by researchers at Rw 01 with a sample of 15 homes found that residents in 10 homes complain of hot air temperature. The type of roof that is used in this study is zinc, asbestos and tile. The goal of researchers wanted to know the relationship type of roof with temperature and humidity bedrooms in the village of Rw 01 District Karangmangu Baturaden Banyumas 2015. This type of research is observational research, analysis using Chi-square test. The study of 30 respondents note that there is a temperature measurement temperature 18 houses and 12 houses qualify the temperature does not qualify while moisture measurement moisture contained 15 houses and 15 houses qualify humidity does not qualify. Results of analysis using Chi-square test that there is a relationship between the type of roof with temperature and humidity. Researchers suggested for further research in order to conduct this research for a longer time.
\end{abstract}

Keywords : healthy home ;temperature; humidity; type of roof; bedroom; environmental health

\section{PENDAHULUAN}

Kenyaman udara dalam ruangan ditentukan berdasarkan hubungan antara suhu udara, kelembaban udara dan gerakan angin (Heinz Frick, dan Tri Hesti Mulyani, 2006, h. 41). Salah satu syarat memenuhi kebutuhan fisiologis rumah yaitu rumah dapat memberikan perlindungan terhadap gangguan cuaca seperti panas, dingin, angin, hujan, dan udara yang lembab.

Suhu dalam rumah yang optimal berkisaran antara $18-30{ }^{\circ} \mathrm{C}$ (Permenkes Nomor 1077 tahun 2011 \& H.J.
Mukono, 2006, h. 158) dan kadar kelembaban yang dipersyaratkan yaitu 40 - 60 \%. (Heinz Frick, Antonius Ardiyanto, dan AMS Darmawan, 2008, h. 47).

Penelitian yang dilakukan Kun Zulaekhatun (2009, h. 54 ), langit - langit berpengaruh terhadap suhu dan kelembaban dalam ruangan. Rudi Gunawan (1994, h. 68) mengemukakan atap bangunan berguna sebagai payung yang melindungi bangunan dibawahnya dari pengaruh panas matahari, hempasan air hujan dan angin. - Kriteria bahan penutup yang baik harus dapat bersifat isolasi terhadap panas, dingin (Vivi Andayani, 2013, h.

1) Email : dargomboz@yahoo.com

2) Email : statistikan@yahoo.com 
2). Survey awal yang dilakukan peneliti di RW 1 dengan sampel 15 rumah ditemukan bahwa warga dalam 10 rumah mengeluhkan suhu udara yang panas.

Tujuan penelitian ini untuk mengetahui "Hubungan Jenis Atap dengan Suhu dan Kelembaban Kamar Tidur di Desa Karangmangu Rw 01 Kecamatan Baturraden Kabupaten Banyumas Tahun 2015”.

\section{BAHAN DAN METODE}

Jenis penelitian ini termasuk penelitian observasional yang mengacu pada deskriptif analitik dengan melakukan pengukuran terhadap variable bebas dan variable terikat kemudian menganalisis data yang terkumpul untuk mencari hubungan antar variabel dengan menggunakan pendekatan Cross sectional untuk melihat apakah ada hubungan antara jenis atap dengan suhu dan kelembaban ruangan.

Sampel yang digunakan dalam penelitian ini adalah $10 \%$ dari jumlah populasi yaitu 30 rumah. Cara pengambilan sampel secara non random sampling yaitu jumlah keseluruhan populasi diambil $10 \%$ dari jumlah populasi secara acak menjadi sampel tanpa undian.

\section{III.HASIL DAN PEMBAHASAN}

\section{Hasil}

Hasil pengukuran suhu kamar diperoleh rata-rata sebesar $29{ }^{\circ} \mathrm{C}$ dengan suhu tertinggi sebesar $32{ }^{\circ} \mathrm{C}$ dan suhu terendah $25^{\circ} \mathrm{C}$ dengan berbagai pemasangan jenis atap ( genteng, asbes, dan seng ). Rata - rata suhu Desa Karangmangu sebesar $29^{\circ} \mathrm{C}$ dan terdapat 18 rumah yang suhunya memenuhi syarat dan 12 rumah suhunya tidak memenuhi syarat.

Hasil pengukuran kelembaban kamar diperoleh rata - rata sebesar $61 \%$ dengan kelembaban tertinggi sebesar 61 \% dan kelembaban terendah 56 \%. Rata rata kelembaban kamar Desa Karangmangu sebesar 60 \% dan terdapat 15 rumah yang kelembabannya memenuhi syarat dan 15 rumah kelembabannya tidak memenuhi syarat.

Jenis atap yang digunakan responden terdapat 13 rumah yang menggunakan genteng dan 17 rumah menggunakan seng dan asbes

Hasil analisis dengan uji Chi square terdapat hubungan antara jenis atap dengan suhu dan kelembaban kamar.

\section{Pembahasan}

Perubahan suhu dalam rumah dapat dipengaruhi oleh ventilasi yang tidak memenuhi syarat, jumlah penghuni, bahan dan struktur bangunan, ketinggian plafon dari lantai. Mengatasi suhu yang tidak optimal langkahnya juga dapat menggunakan atap dan plafon yang dapat menahan panas matahari, dinding tidak lembab. Mengurangi panas di atap akan mempengaruhi suhu ruang yang ada dibawahnya. Atap sebagai ambang batas pada rumah merupakan bagian yang menerima radiasi panas yang paling besar.

Seng terbuat dari logam dimana logam memilki sifat sebagai penghantar panas yang baik sehingga suhu dalam rumah mengalami kenaikan. Asbes juga merupakan penutup atap sejenis seng yang terdiri dari material semen dan serat mineral silikat. Jenis atap genteng biasa bahan dasar pembuatnya adalah tanah liat. Tanah liat memiliki sifat yang lembab dan tahan terhadap panas. Sifat tanah liat pada atap genteng ini menyebabkan panas yang berasal dari sinar matahari tidak akan diteruskan ke dalam rumah sehingga suhu dalam rumah tetap stabil. Atap genteng merupakan insulasi panas yang baik, karena bahan yang tebal dan padat mampu meredam rambatan panas.

Faktor-faktor yang mempengaruhi suhu juga sangat erat dengan faktor-faktor yang mempengaruhi kelembapan udara dalam berbagai hubungan yaitu pengaruh tanah dan air, semakin banyak jumlah uap air baik diudara maupun didalam tanah, maka kelembapan akan semakin tinggi. Atap dengan berbagai desainnya memiliki pengaruh pada tingkat kelembaban pada dinding eksterior (luar) bangunan, karena atap seharusnya bisa mencegah air hujan untuk membasahi dinding luar bangunan. Atap harus tahan terhadap air hujan dan cuaca. Kelembaban dalam bangunan dapat berupa uap air pada bahan bangunan.

\section{IV.SIMPULAN}

Hasil penelitian yang dilakukan terhadap 30 responden terdapat 18 rumah yang suhunya memenuhi syarat dan 12 rumah tidak memenuhi syarat. Hasil penelitian yang dilakukan terhadap 30 responden terdapat 15 rumah yang kelembabannya memenuhi syarat dan 15 tidak memenuhi syarat. Hasil penelitian yang dilakukan terhadap 30 responden terdapat 13 rumah yang jenis atapnya memenuhi syarat (genteng) dan 17 rumah tidak memenuhi syarat (seng dan asbes).

Hasil analisis pengukuran suhu dengan uji Chi square diperoleh nilai Continuity correction sebesar 0,005, maka terdapat hubungan antara jenis atap dengan suhu dan analisis pengukuran kelembaban dengan uji Chi square diperoleh nilai Continuity correction sebesar 0,027, maka terdapat hubungan antara jenis atap dengan kelembaban

Peneliti menyarankan untuk peneliti selanjutnya agar melakukan penelitian ini untuk waktu yang lebih lama.

\section{UCAPAN TERIMA KASIH}

Peneliti mengucapkan terimakasih kepada warga masyarakat Desa Karangmangu Rw 01 Kecamatan Baturraden Kabupaten Banyumas yang telah bersedia menjadi responden yang baik dalam penelitian ini.

\section{DAFTAR PUSTAKA}


Achmad Basuki, 2012, Bahan Penutup Atap, at https://achmadbasuki.wordpress.com.

Ance Gunarsih Kartasapoetra, 2004, Klimatologi Pengaruh Iklim Terhadap Tanah dan Tanaman, Jakarta : PT Bumi Aksara.

Andi A. Wicaksono, 2009, Menciptakan Rumah Sehat, Depok : Penebar Swadaya.

Arda Dinata, 2007, Aspek Teknis Dalam Penyehatan Lingkungan, at http://www.miqrasehat.com.

Diana Barsasella, 2010, Fisika Untuk Mahasiswa Kesehatan, Jakarta : CV Trans Infomedia

Endang Kusman, 2014, Penyebab Panas Dalam Ruang Rumah, http://www.desainrumahsederhana.com.

H.J. Mukono, 2006, Prinsip Dasar Kesehatan Lingkungan, Surabaya : Pusat Penerbitan dan Percetakan Unair (AUP).

Hardi, 2010, Standar Arsitektur Bangunan, at https://hardi91.wordpress.com.

Heinz Frick, Antonius Ardiyanto, dan AMS Darmawan, 2008, Ilmu Fisika Bangunan Pengantar Pemahaman Cahaya Kalor, Kelembaban, Iklim, Gempa Bumi, dan Kebakaran, Yogyakarta : Kanisius.

Heinz Frick, dan Tri Hesti Mulyani, 2006, Arsitektur Ekologis Konsep Arsitektur Ekologis di Iklim Tropis, Penghijauan Kota, dan Kota Ekologis, serta Energi Terbarukan, Yogyakarta : Kanisius.

Hendriyadi, 2012, Menentukan ukuran sampel sederhana, at http://www.teorionline.net.

Hicma Edwin Rosadi, Nurdin Rismansyah , dkk, 2012, Pengaruh Sudut Kemiringan Atap Bangunan Dan Orientasinya Terhadap Kualitas Termal, at http://temuilmiah.iplbi.or.id.

Kun Zulaekhatun, 2008, Pengaruh Ketinggian Langit Langit Terhadap Suhu dan Kelembaban Kamar Tidur di RT 02 RW 01 Desa Lajer Kecamatan Ambal Kabupaten Kebumen.

Lakitan, B., 1994, Dasar Klimatologi, Jakarta : PT Ragagrafindo Persada.
Natalia Ririh, 2012, Mengusir.Lembab.di.Kamar.Mandi Tak Berjendela, at http://www.properti.kompas.com.

Peraturan Menteri Kesehatan Nomor 1077 Tahun 2011 Tentang Pedoman Penyehatan Udara Dalam Ruang Rumah.

Prasatro Satwiko, 2009, Fisika Bangunan, Yogyakarta : CV Andi Offset.

Rekaberu, 2010, Genteng Sebagai Bahan Penutup Atap, at http://rekaberu.blogspot.com.

Rudi Gunawan, 1994, Pengantar Ilmu Bangunan, Yogyakarta : Kanisius.

Rudi Gunawan, 2009, Rencana Rumah Sehat, Yogyakarta : Kanisius.

Soekidjo Notoatmodjo, 2011, Kesehatan Masyarakat Ilmu dan Seni, Jakarta : PT Rineka Cipta.

Tri Cahyono, 2014, Pedoman Penulisan Proposal Penelitian dan Karya Tulis Ilmiah / Skripsi (Edisi Revisi Ketiga).

Vivi Andayani, 2013, Penutup Atap : Bahan Bangunan, at http://www.slideshare.com. 